\title{
Mapping of the interactions between partition proteins Delta and Omega of plasmid pSM19035 from Streptococcus pyogenes
}

Correspondence

Grazyna Jagura-Burdzy

gjburdzy@ibb.waw.pl

Received 9 September 2010

Revised 6 December 2010

Accepted 16 January 2011
Michal Dmowski and Grazyna Jagura-Burdzy

Institute of Biochemistry and Biophysics, Polish Academy of Sciences, Pawinskiego 5A, 02-106 Warsaw, Poland

Formation of the segrosome, a nucleoprotein complex crucial for proper functioning of plasmid partition systems, involves interactions between specific partition proteins (ParA-like and ParBlike), ATP and specific DNA sequences (the centromeric sites). Although partition systems have been studied for many years, details of the segrosome formation are not yet clear. Organization of the pSM19035-encoded partition system is unique; in contrast with other known par systems, here, the $\delta$ and $\omega$ genes do not constitute an operon. Moreover, Omega [a ParB-like protein which has a Ribbon-Helix-Helix $(\mathrm{RHH})$ structure] recognizes multiple centromeric sequences located in the promoters of $\delta, \omega$ and copS (copy-number control gene). The ParA-like protein Delta is a Walker-type ATPase. In this work, we identify the interaction domains and requirements for dimerization and hetero-interactions of the Delta and Omega proteins of pSM19035 plasmid. The $\mathrm{RHH}$ structures are involved in Omega dimerization in vivo and its $\mathrm{N}$-terminal unstructured part is indispensable for association with Delta, both in vivo and in vitro. Omega does not need to form dimers to interact with Delta. ATP binding is not required for Delta dimerization but is important for interaction with Omega in vivo. The in vitro interaction between Delta and Omega depends on ATP but does not require the presence of specific DNA segments (the centromere) recognized by Omega. The C-terminal part of the Delta protein (aa 198-284) is indispensable for interaction with Omega. Delta most probably interacts with Omega as a dimer since two amino acid substitutions in a conserved region between the $A^{\prime}$ and $B$ motifs abolish both the dimerization of Delta and its interaction with Omega.

\section{INTRODUCTION}

Plasmid active partition systems that ensure stable inheritance of low copy number plasmids in dividing cells are composed of three elements: (i) a cis-acting DNA sequence (also called centromere-like region), (ii) a DNAbinding protein (B component) and (iii) an NTPase (A component). The two genes parA and parB usually form an operon regulated by ParA and/or ParB proteins (Gerdes et al., 2000, 2004). Similar systems are engaged in bacterial chromosome partitioning: genome sequencing has confirmed the occurrence of parA-parB operons in close proximity to oriC in the majority of bacterial chromosomes (Bartosik \& Jagura-Burdzy, 2005). However, our understanding of partition processes comes mainly from studies on plasmid-encoded systems.

Abbreviations: DBD, DNA-binding domain; HTH, Helix-Turn-Helix; RHH, Ribbon-Helix-Helix.

Two supplementary figures, a supplementary table of primer sequences and supplementary methods describing plasmid construction are available with the online version of this paper.
Segregation of plasmids by a partition system requires segrosome assembly, which implies interactions between participants. Models of this nucleoprotein complex formation are based on observations of homo- and heterodimerization of both ParA- and ParB-type proteins (Hayes \& Barillà, 2006). The well-studied ParB-like proteins (ParB of P1, SopB of F, KorB of RK2 and ParG of TP228) have been shown to form dimers (Barillà \& Hayes, 2003; Funnell, 1991; Hanai et al., 1996; Williams et al., 1993). Some of them, classified as ParBs of type Ia [large, containing Helix-TurnHelix (HTH) motifs] oligomerize and spread on DNA causing transcriptional silencing. The ParB and SopB proteins of $\mathrm{P} 1$ and $\mathrm{F}$ plasmids, respectively, have been studied extensively, and their interaction domains have been mapped: the dimerization domain is located in the Cterminal part of the protein, whereas interactions with their partner proteins (ParA and SopA) are ensured by the Nterminal parts (Ravin et al., 2003; Surtees \& Funnell, 2001). The dimerization domain of KorB protein of RK2 is also located in its C-terminal part whereas the domain of interaction with IncC (ParA homologue) has been mapped to the central part (Lukaszewicz et al., 2002). 
Partition ParA-like proteins are either Walker-type ATPases, actin-like ATPases (Gerdes et al., 2000) or recently described tubulin-type GTPases (Larsen et al., 2007; Møller-Jensen \& Gerdes, 2007). Walker-type ATPases from partition systems can be divided into two subgroups (Bignell \& Thomas, 2001). The difference between them is the presence of an N-terminal region which contains the HTH motif involved in DNA binding. Longer ParA proteins are components of type Ia plasmid partition systems and are usually involved in regulation of expression of partition genes. However, there are type Ia partition ATPases which do not contain a DNA-binding motif in the $\mathrm{N}$ terminus (IncC1 of RK2) or exist only in a shorter form like IncC of RA3 (IncU) (Kulinska et al., 2008) and chromosomally encoded ParA proteins (Lasocki et al., 2007; Leonard et al., 2005; Quisel \& Grossman, 2000). In type Ib partition systems, ParA-like proteins are usually not transcriptional regulators and do not contain $\mathrm{N}$-terminal DNA binding regions. The ParA-like proteins, regardless of their type, can dimerize, polymerize and form filaments (Akhtar et al., 2009; Barillà et al., 2005; Bouet et al., 2007; Lim et al., 2005; van den Ent et al., 2002).

Detailed studies of the dimerization of ParA-like proteins have been conducted for some representative proteins of the ParA-family, mainly of type Ia. It has been shown that dimer formation by ParA from P1 plasmid is induced by ATP binding and that ADP, as well as non-hydrolysable analogues, can promote DNA binding (Davey \& Funnell, 1994). Studies of K122E mutant ParA from P1 showed that this substitution did not alter the protein configuration, but reduced the ATPase activity. Moreover, this protein was defective in DNA binding regardless of the presence of ATP and thus could not regulate the par operon (Davis et al., 1996; Li et al., 2004). Later, Fung et al. (2001) suggested that the lysine substitution altered the the ability of ParA to bind ATP. The observation that ATP binding, but not hydrolysis, reinforces ParA repressor activity has strengthened this suggestion. All these findings support Bouet \& Funnell (1999), who concluded that both ADP and ATP mediate dimerization of P1 ParA and the two nucleotides act as a switch; ADP-bound ParA acts as a repressor, whereas ATP-bound ParA is involved in partition activity. Moreover, a K16E derivative of ParA from the Vibrio cholerae chromosome (position equivalent to K122 of ParA of P1; see Supplementary Fig. S1, available with the online version of this paper) was unable to ensure partition, and visualization by fluorescence microscopy demonstrated its homogeneous distribution and a lack of foci (Fogel \& Waldor, 2006). Those observations probably reflected the fact that ATP binding stimulates ParA-like protein polymerization, as observed for MinD (Suefuji et al., 2002), ParF (Barillà et al., 2005) and SopA (Bouet et al., 2007; Lim et al., 2005). A study of ParA-like protein Soj from Thermus thermophilus confirmed that a K20A substitution (in a position equivalent to K122 of ParA of P1; see Supplementary Fig. S1) abolished ATP hydrolysis due to the inability to bind the nucleotide (Leonard et al.,
2005). The same study also showed that Soj needs ATP for dimerization and that ATP hydrolysis promotes the dissociation of dimers. These observations explain why wild-type and K20A Soj did not dimerize (the former hydrolysed ATP whereas the latter did not bind it). Another Walker-type ATPase, the UvrA ATPase, a subunit of the DNA repair enzyme $\mathrm{ABC}$, has also been shown to be defective when carrying a K37A substitution (Myles et al., 1991).

The interactions of ParA-like proteins with ParB-like proteins have been studied in some partition systems only. The few detailed mutational studies of partition protein interactions concerned mainly type Ia systems (Walkertype ATPases with a DNA-binding function and ParB-like proteins with HTH DNA-binding motifs). ParB of Ia stimulates both the ATPase activity of ParA (Davey \& Funnell, 1997) and the polymerization of ParA-like proteins (Barillà et al., 2007; Bouet et al., 2007; Machón et al., 2007) crucial for separation of plasmid molecules. In the systems studied, it has been demonstrated that both proteins are able to interact with each other only in the dimeric form (Bouet \& Funnell, 1999).

We analysed Delta and Omega proteins, components of the partition system of pSM19035 plasmid, a low-copy-number plasmid isolated from Streptococcus pyogenes (Behnke et al., 1979). The two genes, $\delta$ and $\omega$, are transcribed separately, which is unique among the partition systems studied so far (Dmowski et al., 2006). Nevertheless, the tight co-expression of the two partition genes is ensured by their common regulator, the Omega protein. This transcriptional repressor binds to repeated heptameric sequences WATCACW situated in promoter regions in various arrangements. Besides plasmid partitioning, Omega also regulates the plasmid copy number (copS gene) and expression of the $\omega-\varepsilon-\zeta$ operon that encodes the toxin-antidote system of pSM19035 (de la Hoz et al., 2000; Zielenkiewicz \& Ceglowski, 2005). Any of the three Omega-binding regions (PcopS, $P \delta$ and $P \omega$ ) may act as a centromeric sequence (Dmowski et al., 2006).

Crystal structures of Delta (Murayama et al., 2001) and Omega (Pratto et al., 2008) proteins have been solved. The Delta protein is a Walker-type ATPase and its activity is stimulated by Omega protein. In the presence of Omega and ATP, Delta polymerizes. Sitkiewicz (2002) detected Delta dimerization in the yeast two-hybrid system, but failed to demonstrate its associations with Omega as well as Omega dimerization. The Omega protein of the pSM19035 plasmid does not share sequence similarity with ParB-like proteins. It is a small, 71 aa protein $(\sim 8 \mathrm{kDa})$ whose crystal structure shows similarity to the Arc/MetJ family of repressors. Proteins from this family bind DNA and form a Ribbon-Helix-Helix (RHH) structure (reviewed by Schreiter \& Drennan, 2007). Such proteins have also been found to act as ParB-like components of type Ib bacterial partition systems, as in plasmids TP228 (Golovanov et al., 2003) and pB171 (Ringgaard et al., 2007), and type II 
partition systems from pSK41 (Schumacher et al., 2007) and pB171 (Møller-Jensen et al., 2007) (Supplementary Fig. S2, available with the online version of this paper).

In this work we analysed in vivo and in vitro associations of Delta and Omega proteins related to those found in type $\mathrm{Ib}$ systems. Regions involved in dimerization of each protein and interaction with their partners were defined.

\section{METHODS}

Bacterial strains. The bacterial strains used in this work were Escherichia coli $\mathrm{DH} 5 \alpha\left\{\mathrm{F}^{-}\right.$, gyrA96, recA1, relA1, endA1, thi1, hsdR17, supE44, deoR, $\Delta$ (lacZYA-argF)U169, [980 $\Delta$ (lacZ)M15]\} (Hanahan, 1983), E. coli GS1129 [MC4100 pheA905 $\lambda$ (sulA::lacZ); kindly provided by G. V. Stauffer] and E. coli BL21(DE3) $\left[\mathrm{F}^{-}\right.$ompT $h s d \mathrm{~S}_{\mathrm{B}}\left(\mathrm{r}_{\mathrm{B}}^{-} \mathrm{m}_{\mathrm{B}}^{-}\right)$gal dcm BL21(DE3); Studier \& Moffatt, 1986].

Plasmid construction. The plasmids and primers used in this work are listed in Table 1 and Supplementary Table S1 (available with the online version of the paper), respectively. If not indicated otherwise, plasmid pDO1000 was used as the template for amplification of studied genes by PCR. Standard plasmid DNA isolation, modification and PCR amplification, as well as PCR mutagenesis by overlap extension and site-directed mutagenesis, were used as described by Sambrook \& Russell (2001). Details of the plasmid construction are available online as Supplementary Methods.

Bacterial growth and transformation. E. coli strains were routinely grown in L broth (liquid or solidified with $1.5 \%$ agar) at $37{ }^{\circ} \mathrm{C}$ (Sambrook \& Russell, 2001). When necessary, antibiotics were added at the following concentrations: $100 \mu \mathrm{g}$ ampicilin $\mathrm{ml}^{-1}, 20 \mu \mathrm{g}$ tetracycline $\mathrm{ml}^{-1}, 20 \mu \mathrm{g}$ kanamycin $\mathrm{ml}^{-1}$. E. coli strains were transformed according to standard procedures (Sambrook \& Russell, 2001) and plated on L agar plates supplemented with an appropriate antibiotic.

Determination of $\boldsymbol{\beta}$-galactosidase activity in $\boldsymbol{E}$. coli cells. The $\beta$ galactosidase activity of E. coli GS1129 strain containing appropriate plasmids was determined as described by Miller (1992). Each plasmid pair was analysed at least in triplicate.

Protein overexpression and purification. An overnight culture of E. coli BL21(DE3) transformant was diluted 1:100 in $50 \mathrm{ml}$ fresh $\mathrm{L}$ broth supplemented with appropriate antibiotic. This new culture was aerated at $30{ }^{\circ} \mathrm{C}$ until $\mathrm{OD}_{600} 0.6-0.8$. Then, IPTG was added to $1 \mathrm{mM}$ final concentration and the culture was aerated for another $2 \mathrm{~h}$ at $30{ }^{\circ} \mathrm{C}$. The $6 \times$ His-tagged proteins were purified under native conditions using the Protino Ni-TED 1000 system (MachereyNagel) according to the manufacturer's instructions, except the elution step which was done using LEW buffer $\left(50 \mathrm{mM} \mathrm{Na}_{2} \mathrm{HPO}_{4}\right.$, $300 \mathrm{mM} \mathrm{NaCl})$ with increasing amounts of imidazole $(25,50,100$, 200, $250 \mathrm{mM}$ ). Protein concentration was determined by using the Bradford assay (Bradford, 1976).

Co-purification of Delta and Omega proteins. Purified $6 \times$ Histagged Omega protein eluted with $2 \mathrm{ml}$ LEW buffer containing $25 \mathrm{mM}$ imidazole was used for copurification of its partner using the Protino Ni-IDA 150 system (Macherey-Nagel). The $6 \times$ His-tagged Omega $(\sim 0.15 \mathrm{mg})$ was mixed with the soluble fraction of proteins from bacterial cells overproducing the Delta protein $(\sim 1 \mathrm{mg})$. When indicated, $P \delta$ DNA amplified using primers FHindIII and RPstI $(\sim 10 \mathrm{ng})$ and/or ATP (final concentration $1.25 \mathrm{mM})$ was added. As a control, the supernatant was also mixed with purified $6 \times$ His-tag. After 15 min incubation at room temperature, mixtures were loaded on Protino Ni-IDA 150 columns. The flow-through was collected, the column washed with $2 \times 250 \mu$ LEW buffer and then treated with LEW buffer supplemented with increasing amounts of imidazole (25, $50,100,150,200$ and $250 \mathrm{mM})$.

Protein electrophoresis. Proteins were separated by using SDSPAGE (Laemmli, 1970) with modifications allowing separation of small proteins in $15 \%$ polyacrylamide gels as described by Schägger \& von Jagow (1987). Gels were silver stained as described by Morrissey (1981).

Western blot analysis. Proteins were electro blotted onto nitrocellulose (Optiran BA-S 83, Schleicher \& Schuell) using the semi-dry transfer procedure. Immunological detection was performed using the SNAP i.d. protein detection system (Millipore) according to the manufacturer's recommendations. As primary antibody, anti-Delta serum (Kucharczyk TE) was used. ImmunoPure alkaline-phosphataseconjugated goat anti-rabbit IgG (Pierce Biotechnology) was used as the secondary antibody and detected with CDP-Star (Roche).

\section{RESULTS}

Delta and Omega interactions in vivo were analysed in a bacterial two-hybrid system based on the LexA repressor (Dimitrova et al., 1998). The N-terminal part (70 aa) of protein LexA constitutes the DNA-binding domain (DBD) while the C-terminal part is responsible for LexA dimerization, a step essential for LexA repressor activity. One of the proteins analysed in this system is fused to the N-terminal part of the wild-type version of the LexA protein $\left(\operatorname{LexA}{ }^{\mathrm{WT}}\right)$, whereas the other is fused to a modified version of the $\mathrm{N}$ terminus of LexA $\left(\operatorname{LexA}^{408}\right)$. LexA ${ }^{\mathrm{WT}}$ recognizes the wildtype half of the operator sequence, while LexA ${ }^{408}$ binds to the modified half of the LexA operator inserted in the PlacZ upstream of the $\beta$-galactosidase gene in E. coli GS1129. The LexA repressor can be reconstituted only when there is interaction between proteins to which LexA ${ }^{\mathrm{WT}}$ and LexA $\mathrm{A}^{408}$ are fused. Repression of the lacZ expression by LexA is indicative of an interaction of the proteins studied. Protein interaction was analysed by measuring the $\beta$-galactosidase activity in E. coli GS1129 harbouring pDP804 and pMS604 plasmid derivatives carrying genes encoding proteins of interest fused to the two forms of LexA. The level of $\beta$ galactosidase activity (in Miller units) was measured and calculated as the percentage of the activity obtained for the GS1129 strain carrying two empty vectors, pMH723 and pMH724 (100\%), where the lacZ gene was unrepressed. The analysis of Delta and Omega variants gave similar results regardless of the variant of LexA they were fused to.

\section{Delta protein dimerization}

For Delta dimerization analysis in the bacterial two-hybrid system, plasmids pMS2000 (LexA ${ }^{\mathrm{WT}}$ Delta) and pDP2000 (LexA ${ }^{408}$ Delta) were simultaneously introduced into the $E$. coli GS1129 strain. As a control, strains carrying pairs of plasmids - pMH723 + pMH724, pMH723 + pMS2000 or pDP2000 + pMH724 - were used. The enzyme activity in strains carrying an empty vector combined with $\delta$ encoding plasmid was the same as that of the strain with two empty vectors, whereas it dropped to $50 \%$ in a strain containing the two LexA-Delta fusion-encoding plasmids 
Table 1. Plasmids used in this work

Details of plasmid construction are given in the text and in Supplementary Methods, available with the online version of this paper.

\begin{tabular}{|c|c|c|}
\hline Plasmid & Relevant feature & Source/reference \\
\hline \multicolumn{3}{|c|}{ pDP804 derivatives } \\
\hline pDP804 & $\begin{array}{l}\text { Bacterial two-hybrid system vector, carries translational fusion of LexA } \mathrm{A}_{1-87} 408 \text {-Jun } \\
\text { zipper (triple substitution P40A-N41S-A42S), p15A replicon, } \mathrm{Ap}^{\mathrm{R}}\end{array}$ & Dimitrova et al. (1998) \\
\hline pDP2000 & LexA $_{1-87} 408$-Delta translational fusion ( $\delta$ gene cloned as $B s s \mathrm{HII}-B g l \mathrm{II}$ fragment) & This work \\
\hline pDP4000 & LexA $_{1-87} 408$-Omega translational fusion ( $\omega$ gene cloned as $B s s \mathrm{HII}-B g l \mathrm{II}$ fragment) & This work \\
\hline pDP4030A & LexA $_{1-87} 408-O m e g a \mathrm{~V} 30 \mathrm{~A}, \mathrm{~V} 32 \mathrm{~A}$ translational fusion & This work \\
\hline pDP4039A & LexA $_{1-87} 408-O m e g a$ I39A, I40A translational fusion & This work \\
\hline pDP4059A & LexA $_{1-87} 408-O m e g a$ L59A, I63A translational fusion & This work \\
\hline pMH723 & pDP804 derivative with 408-Jun zipper gene deleted by digestion with $B s s \mathrm{HII}$ and BglII & Lochowska et al. (2004) \\
\hline \multicolumn{3}{|c|}{ pET28a + derivatives } \\
\hline $\mathrm{pET} 28 \mathrm{a}+$ & ori $_{\mathrm{ColE} 1}, \mathrm{Km}^{\mathrm{R}}, \mathrm{T} 7 p$ & Novagen \\
\hline $\mathrm{pET} \delta$ & $\mathrm{T} 7 p-\delta$ & This work \\
\hline $\mathrm{pET} \delta 36 \mathrm{~A}$ & $\mathrm{~T} 7 p-\delta \mathrm{K} 36 \mathrm{~A}$ & This work \\
\hline $\mathrm{pET} \delta 60 \mathrm{~A}$ & $\mathrm{~T} 7 p-\delta \mathrm{D} 60 \mathrm{~A}$ & This work \\
\hline $\mathrm{pET} \omega \mathrm{H}$ & T7p- $\omega$, C-terminal $6 \times$ His tag & This work \\
\hline $\mathrm{pET} \omega 5 \mathrm{NH}$ & T7p- $\omega \Delta 2-5$, C-terminal $6 \times$ His tag & This work \\
\hline pET $\omega 39 A H$ & T7p- $\omega$ I39A, I40A, C-terminal $6 \times$ His tag & This work \\
\hline pET $\omega 59$ AH & T7p- $\omega$ L59A, I63A, C-terminal $6 \times$ His tag & This work \\
\hline \multicolumn{3}{|c|}{ pMS604 derivatives } \\
\hline pMS604 & $\begin{array}{l}\text { Bacterial two-hybrid system vector, carries translational fusion of LexA }{ }_{1-87} \text { WT-Fos } \\
\text { zipper, ori }{ }_{\text {ColE1 } 1}, \mathrm{Tc}^{\mathrm{R}}\end{array}$ & Dimitrova et al. (1998) \\
\hline pMS2000 & LexA $_{1-87}$ WT-Delta translational fusion ( $\delta$ gene cloned as BstEII-XhoI fragment) & This work \\
\hline pMS2023 & LexA $_{1-87}$ WT-Delta $\Delta 24-39$ translational fusion & This work \\
\hline pMS2036A & LexA $_{1-87}$ WT-Delta K36A translational fusion & This work \\
\hline pMS2036E & LexA $_{1-87}$ WT-Delta K36E translational fusion & This work \\
\hline pMS2060A & LexA $_{1-87}$ WT-Delta D60A translational fusion & This work \\
\hline pMS2104A & LexA $_{1-87}$ WT-Delta L104A, I105A translational fusion & This work \\
\hline pMS2198 & LexA $_{1-87}$ WT-Delta $\Delta 198-284$ translational fusion & This work \\
\hline pMS4000 & LexA $_{1-87}$ WT-Omega translational fusion ( $\omega$ gene cloned as $B s t$ EII-XhoI fragment) & This work \\
\hline pMS4001A & LexA $_{1-87}$ WT-Omega V1A translational fusion & This work \\
\hline pMS4002A & LexA $_{1-87}$ WT-Omega I2A translational fusion & This work \\
\hline pMS4005 & LexA $_{1-87}$ WT-Omega $\Delta 2-5$ translational fusion & This work \\
\hline pMS4010 & LexA $_{1-87}$ WT-Omega $\Delta 2-10$ translational fusion & This work \\
\hline pMS4018 & LexA $_{1-87}$ WT-Omega $\Delta 2-18$ translational fusion & This work \\
\hline pMS4023A & LexA $_{1-87}$ WT-Omega I2A, V3A translational fusion & This work \\
\hline pMH724 & pMS604 derivative with WT-Fos zipper gene deleted by digestion with BstEII and XhoI & Lochowska et al. (2004) \\
\hline \multicolumn{3}{|c|}{ pUC18 derivatives } \\
\hline pUC18 & E. coli general cloning vector ori $_{\mathrm{ColE} 1}, \mathrm{Ap}^{\mathrm{R}}$ & Yanisch-Perron et al. (1985) \\
\hline pDO1000 & $\delta$ and $\omega$ genes cloned into HindIII-EcoRI restriction sites & Dmowski et al. (2006) \\
\hline pDO4000 & $\begin{array}{l}\text { HindIII-EcoRI DNA fragment from pMS4000 }\left(\mathrm{LexA}_{1-87} \mathrm{WT}-\mathrm{Omega}\right. \\
\text { translational fusion) }\end{array}$ & This work \\
\hline
\end{tabular}

(Fig. 1). These results demonstrate that Delta is capable of dimerization in vivo.

Analysis of other A-type proteins involved in plasmid partitioning has demonstrated a role for ATP binding and/ or hydrolysis in protein dimerization (Davey \& Funnell, 1994; Fung et al., 2001; Leonard et al., 2005). To elucidate the role of the Walker A and $\mathrm{A}^{\prime}$ motifs in Delta dimerization we have chosen the most conserved residues in the motif $A$ and $\mathrm{A}^{\prime}$ in ParA-like ATPases. Plasmids pMS2036A and pMS2036E encode Delta with the Lys36 residue substituted by alanine (K36A) or glutamic acid (K36E), respectively.
Another pMS2000 plasmid derivative, pMS2023, encoding Delta lacking aa 24-39 (the Walker A motif of ATPase) was also constructed. The fourth $\delta$ allele had the conserved Asp60 residue in the $\mathrm{A}^{\prime}$ motif substituted by alanine (plasmid pMS2060A producing Delta D60A). The four mutant plasmids, paired with pDP2000, were used for transformation of E. coli GS1129 and the $\beta$-galactosidase activity in the transformants was analysed. None of the Lys36 substitutions studied abolished Delta dimerization; the relative lac $Z$ activities were $36 \%(\mathrm{~K} 36 \mathrm{~A})$ and $37 \%$ (K36E) (Fig. 2a, i). In contrast, deletion of the Walker A motif (pMS2023) abolished Delta protein dimerization. The possibility that 


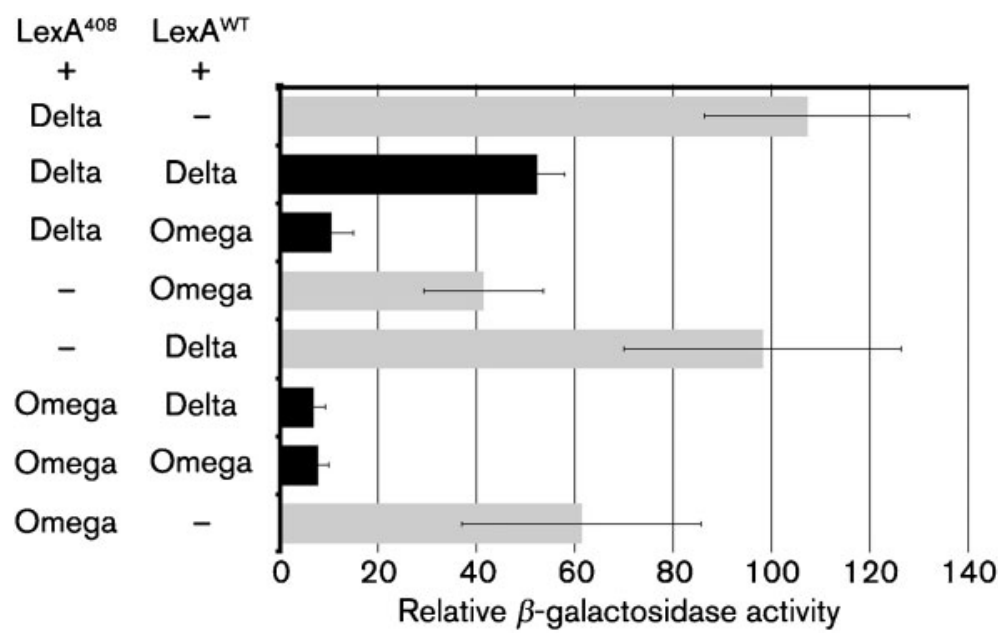

Fig. 1. Delta and Omega protein interactions in the bacterial two-hybrid system. $\beta$ Galactosidase activity was assayed in strains harbouring pairs of plasmids encoding fusions of LexA DBDs with Delta or Omega. The activity is presented relative to the lac $Z$ activity measured in E. coli GS1129 with pMH723 and pMH724 (100\%). LexA ${ }^{408}$ Delta ${ }^{W T}$ fusion was expressed from pDP2000, LexA ${ }^{\text {WT }}$ Delta ${ }^{\text {WT }}$ fusion from pMS2000, LexA ${ }^{\text {WT }}$ Omega ${ }^{W T}$ fusion from pMS4000 and LexA ${ }^{408}$ Omega ${ }^{W T}$ fusion from pDP4000. Error bars show SD.

such a deletion causes an extensive conformational change of Delta cannot be excluded. Delta dimerization was also unaffected by the D60A mutant (plasmid pMS2060A); the relative $\beta$-galactosidase activity was $49 \%$ (Fig. $2 \mathrm{a}$, i).

In a study of Pseudomonas aeruginosa partition proteins, a region of $\mathrm{ParA}_{P . a}$ protein involved in both dimerization and interaction with its partner $\operatorname{ParB}_{P . a}$ was identified (K. Lasocki and G. Jagura-Burdzy, unpublished data). Alignment of the ParA $A_{\text {P.a. }}$ and Delta amino acid sequence indicated the homologous region of Delta (Supplementary Fig. S1). For further analysis, two residues from this region (Leu104 and Ile105) were selected for substitution. Plasmid pMS2104A (Delta L104A, I105A) was constructed and the relative $\beta$-galactosidase activity was measured in the E. coli GS1129 derivative carrying this plasmid together with pDP2000 (Fig. 2a, i). The unrepressed level of $\beta$ galactosidase activity $(106 \%)$ indicated that this double substitution abolished Delta dimerization. The soluble fractions of extracts from strains tested in the bacterial two hybrid system were screened by Western blotting with antiDelta antibodies (Supplementary Fig. S3, available with the online version of this paper). The levels of LexA-Delta and LexA-Delta L104A I105A hybrid proteins were comparable, excluding the possibility that lack of self-interactions is due to the instability of such a Delta variant.

In order to analyse the role of the $\mathrm{C}$ terminus of Delta protein in its dimerization, plasmid pMS2198 (Delta lacking the 86 C-terminal residues) was analysed. Its analysis in the bacterial two-hybrid system revealed that the $\mathrm{C}$ terminus does not play an important role in Delta dimerization: the relative $\beta$-galactosidase activity in the E. coli GS1129 strain carrying pMS2198 and pDP2000 plasmids constituted $62 \%$ of the control strain carrying empty vectors (intact Delta gives repression to $55 \%$ ) (Fig. 2a, i).

\section{Omega protein dimerization}

To analyse the ability of Omega protein to dimerize in vivo, plasmids pMS4000 (LexA ${ }^{\mathrm{WT}}$ Omega) and pDP4000
(LexA ${ }^{408}$ Omega) were used for transformation of E. coli GS1129. Interestingly, strains with a combination of an empty vector and one LexA-Omega fusion showed some lac $Z$ repression; this was $42-62 \%$ of the lac Z activity detected in the strain with empty vectors. The relative $\beta$ galactosidase activity of the strain containing Omega fused with two LexA DBDs was six- to ninefold lower than that observed in the strain with a single LexA-Omega fusion (Fig. 1). These results indicate that the assay can be used to demonstrate Omega-Omega interaction in vivo.

First, the role of the flexible $\mathrm{N}$ terminus of Omega in its dimerization was studied. For this, plasmids pMS4005, pMS4010 and pMS4018 encoding Omega variants deprived of 4, 9 or $17 \mathrm{~N}$-terminal amino acids, respectively, were prepared. The $\beta$-galactosidase activity of E. coli GS1129 strains carrying either of these plasmids coupled with the pDP4000 plasmid encoding the intact Omega protein was analysed (Fig. 2b, ii). The results demonstrated that the removal of 4, 9 or even 17 amino acid residues from the $\mathrm{N}$ terminus had no effect on Omega dimerization $(10,13$ and $10 \% \beta$-galactosidase activity, respectively, compared with intact Omega, $7 \%$ ).

On the basis of the crystal structure of Omega protein it has been previously suggested that hydrophobic residues located in both ribbon and helix structures are involved in protein dimerization (Murayama et al., 2001). In order to verify the role of the $\beta, \alpha 1$ and $\alpha 2$ structures in Omega dimerization, three Omega derivatives with pairs of hydrophobic amino acids from these regions converted into alanines were constructed (Supplementary Fig. S2). E. coli GS1129 was transformed with plasmid pMS4000 paired with one of the following plasmids: pDP4030A (Val30 and Val32 converted into alanines), pDP4039A (Ile39 and Ile40 converted into alanines) and pDP4059A (Leu59 and Ile63 converted into alanines). Analysis of $\beta$-galactosidase activity expressed in such strains showed that abrogation of potential hydrophobic interactions in any of the secondary structures investigated had a negative effect on Omega dimerization. The substitutions in the $\beta, \alpha 1$ and $\alpha 2$ 
(a)

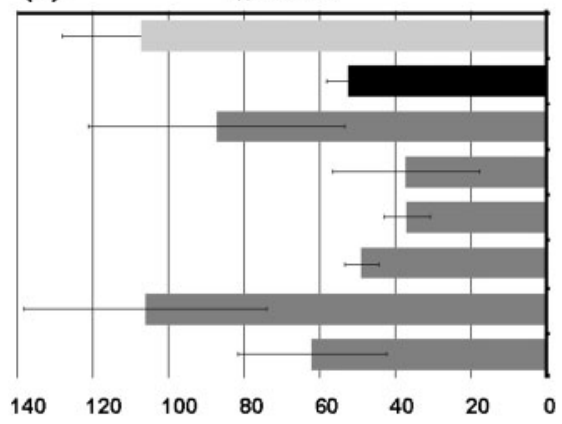

(ii) Omega

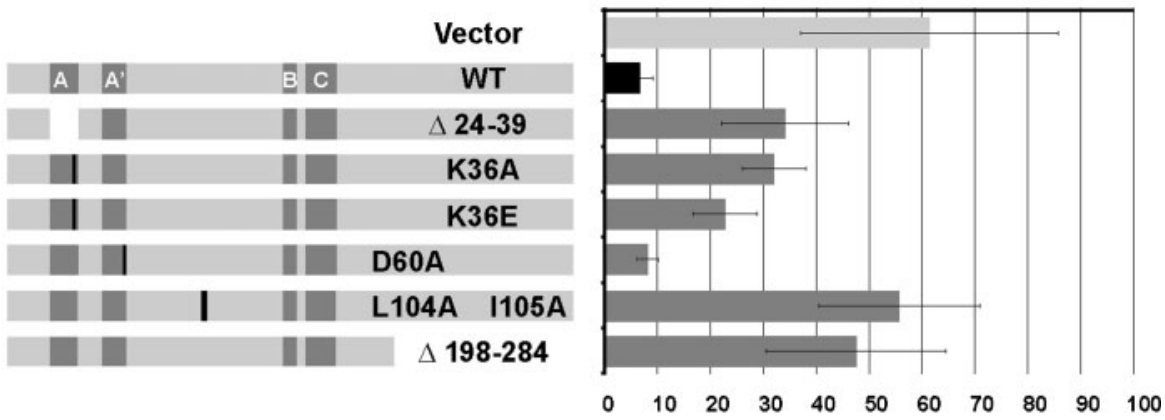

(b)
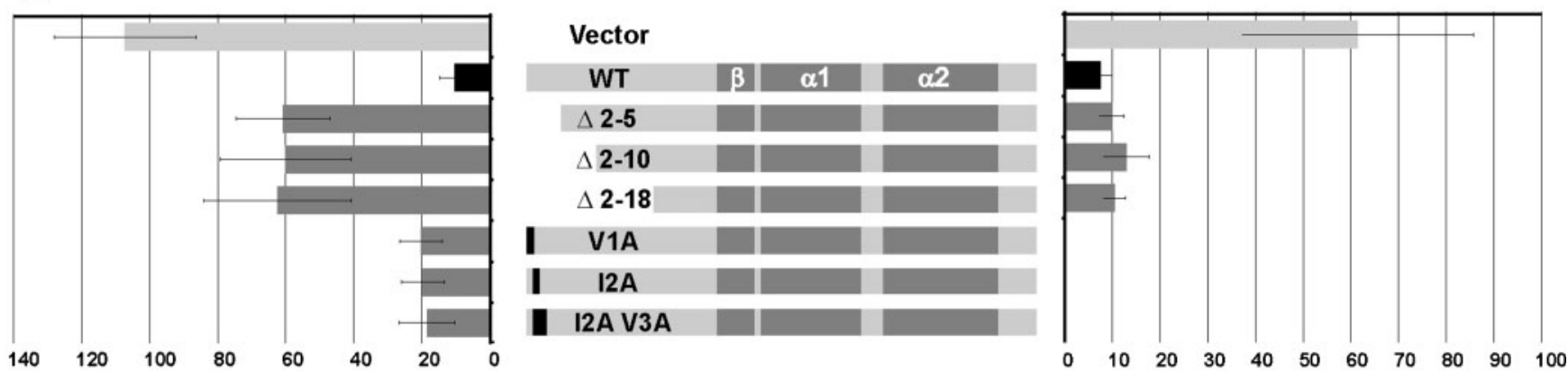

(c)

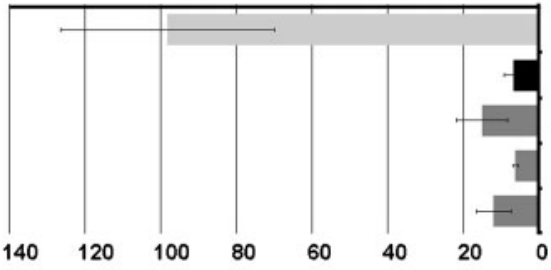

Relative $\beta$-galactosidase activity
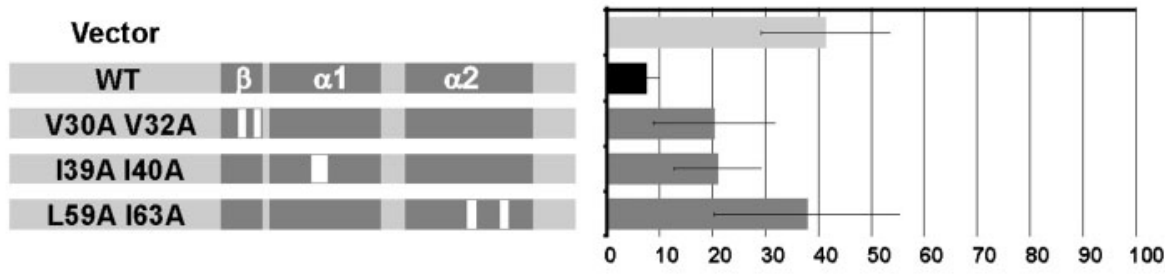

Relative $\beta$-galactosidase activity

Fig. 2. Dimerization and hetero-interactions of Delta and Omega protein variants in bacterial two-hybrid system. $\beta$ Galactosidase activity was assayed in E. coli GS1129 harbouring pairs of plasmids carrying: (a) alleles encoding Delta variants fused with LexA ${ }^{W T}$ in combination with Delta or Omega fused with LexA ${ }^{408}$ (similar results were obtained when Delta variants were fused with LexA $\left.{ }^{408}\right)$; (b) alleles encoding Omega variants modified in the $\mathrm{N}$-terminal part fused with LexA $\mathrm{WT}^{\text {in }}$ combination with Delta or Omega fused with LexA ${ }^{408}$ (similar results were obtained when Omega variants were fused with LexA ${ }^{408}$ ); (c) alleles encoding Omega variants modified in the $\mathrm{RHH}$ structures fused with LexA ${ }^{408}$ in combination with Delta or Omega fused with LexA ${ }^{W T}$ (similar results were obtained when Omega variants were fused with LexA ${ }^{W T}$ ). $\beta$-Galactosidase activity is presented relative to that in E. coli GS1129 harbouring plasmids encoding LexA domain only (pMH723 and pMH724; $100 \%$ ). Modifications introduced in Delta and Omega proteins are shown. Error bars show SD.

regions roughly halved the ability of Omega to dimerize (Fig. 2c, ii).

\section{Delta and Omega protein interaction}

Models of plasmid partition predict a direct interaction between the ParA-like and ParB-like proteins. To investigate the interaction between Delta and Omega proteins, pairs of plasmids pDP2000+pMS4000 and pDP4000+pMS2000 were introduced into $E$. coli GS1129 to use the $\beta$-galactosidase activity as a measure of the Delta-Omega interaction. The lac $Z$ activity in strains carrying the Delta and Omega fusions with LexA DBDs represented 7 and $10 \%$ of the $\beta$ galactosidase activity found in cells carrying empty vectors (Fig. 1), indicating a strong interaction between the two proteins. Thus, the LexA-based bacterial two-hybrid system proved very useful for monitoring the interaction of Delta and Omega proteins in vivo.

The association of Delta and Omega proteins was also analysed in vitro. Purified Omega protein with a $6 \times$ His-tag at the C-terminal end (produced from $\mathrm{pET} \omega \mathrm{H}$ ) was coupled 
(a)

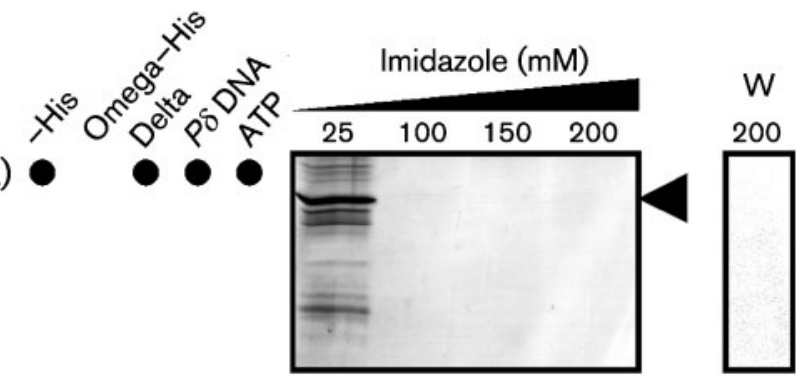

(b)
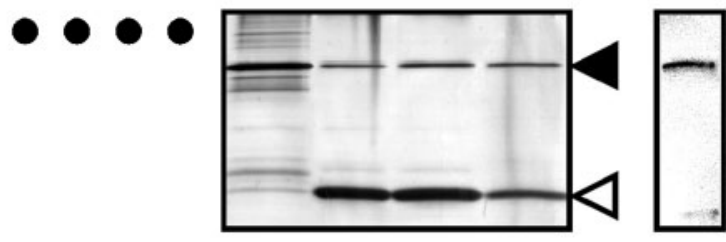

(c)
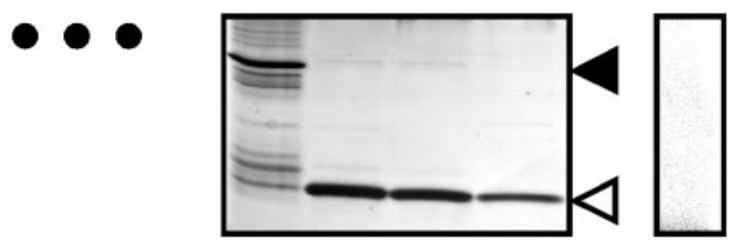

(d)

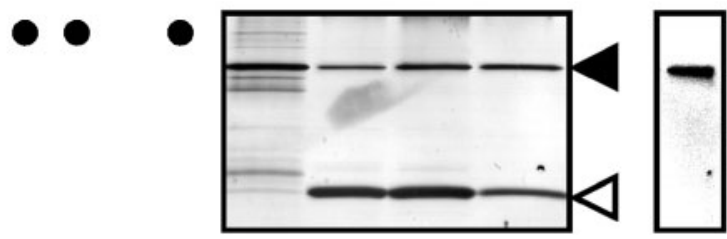

Fig. 3. Association of Delta and Omega proteins in vitro. Purified Omega $-6 \times$ His protein was mixed with soluble fraction of proteins obtained from a Delta overproducing strain BL21(DE3) $\mathrm{pET} \delta$. Where indicated, ATP (1.25 mM) and DNA fragment with Omegabinding sites $(P \delta)$ were added to the mixture before column loading. Eluates obtained with increasing imidazole concentrations in wash buffer $(25,100,150$ and $200 \mathrm{mM})$ were separated by SDS-PAGE and silver stained. The composition of the incubation mixtures $(a-d)$ is indicated on the left. Black and white arrowheads indicate positions of Delta and Omega on the gel, respectively. W, Immunodetection of Delta with anti-Delta antibodies in eluate with $200 \mathrm{mM}$ imidazole.

with Delta in a native form (produced from $\mathrm{pET} \delta$ ). In the control experiment, the purified Omega $-6 \times$ His was replaced with a purified short polypeptide with a $6 \times$ Histag $($ pET28a +$)$. Each protein mixture was supplemented with ATP and Omega-binding DNA sequences ( $P \delta$ region). In the presence of Omega-His, the binding of Delta to $\mathrm{Ni}^{2+}$ agarose was strong, as it remained attached to the column even in the presence of $150 \mathrm{mM}$ imidazole (Fig. 3b). In the control experiment (Delta coupled with $6 \times$ His), Delta could be eluted at $25 \mathrm{mM}$ imidazole (Fig. 3a), indicating that the interaction of Delta with the resin was dependent on the presence of Omega.

In order to examine whether exogenous ATP or Omegabinding DNA sequences are necessary for the Delta-Omega interaction, mixtures deprived of one of these components were prepared and treated as above. This experiment showed that omitting ATP in the mixture resulted in a decreased Delta affinity to the column, similar to that observed when Delta was incubated with the short polypeptide with $6 \times$ His alone (Fig. 3c). In contrast, the absence of the $P \delta$ region had no negative influence on the Delta binding to $\mathrm{Ni}^{2+}$-agarose with immobilized Omega$6 \times$ His (Fig. 3d). These results indicate that ATP is required for Omega association with Delta in vitro, whereas Omega-binding DNA sequences are not.

To analyse the role of the Walker A and $\mathrm{A}^{\prime}$ motifs in Delta interaction with Omega, plasmids pMS2036A, pMS2036E, pMS2023 and pMS2060A (which produce Delta variants able to dimerize) were used for co-transformation of $E$. coli GS1129 together with plasmid pDP4000 (LexA ${ }^{408}$ Omega $^{\text {WT }}$ ). Both substitutions of Lys36 as well as the removal of the ATPase motif A substantially decreased the ability of Delta to interact with Omega. The relative lac $Z$ activities were $32 \%$ (DeltaK36A-Omega), $23 \%$ (DeltaK36E-Omega) and 34\% (Delta $\Delta$ WA-Omega) compared with $7 \%$ activity in the presence of DeltaWT-Omega (Fig. 2a, ii). Single substitution of Asp60 had no effect on the Delta interaction with Omega; the relative $\beta$-galactosidase activity was $8 \%$ (DeltaD60AOmega) (Fig. 2a, ii).

Delta variants carrying substitutions in the Walker A or $\mathrm{A}^{\prime}$ motifs were also tested for their interaction with Omega in vitro. Two Delta derivatives were produced from plasmids pET $36 \mathrm{~A}$, pET $\delta 60 \mathrm{~A}$ and mixed with Omega- $6 \times$ His in the presence of ATP. DeltaK36A was unable to bind Omega (Fig. 4c). In contrast, DeltaD60A seemed to be unaffected in Omega protein binding (Fig. 4d).

We also analysed a Delta variant with substitutions in the region between motifs $\mathrm{A}^{\prime}$ and B (Delta L104A, I105A), which compromise Delta dimerization. When the pMS2104A plasmid was tested in a pair with plasmid pDP4000 (LexA ${ }^{408}$ Omega), the relative $\beta$-galactosidase activity was $56 \%$ (Fig. 2a, ii), indicating that Delta loses the ability to interact with Omega at the same time as the dimerization defect appears.

Deletion of 86 C-terminal amino acids had no effect on Delta dimerization. The role of the C-terminal part of the Delta protein was analysed by using plasmid pMS2198 (Delta $\Delta 198-284$ ) co-introduced with pDP4000. Removal of the $86 \mathrm{C}$-terminal residues from Delta had a negative effect on its ability to interact with Omega ( $\beta$-galactosiadase activity $48 \%$ of control) (Fig. 2a, ii). This value is similar to that $(61 \%)$ obtained when an empty vector was coupled with pDP4000 (LexA ${ }^{408}$ Omega). This clearly demonstrates that the C-terminal deletion analysed abolished the ability of Delta to interact with Omega.

Analysis of the crystal structure of ParG - a protein which folds into an RHH structure, similarly to Omega - has indicated that the unstructured $\mathrm{N}$-terminal tail and $\alpha$ helical regions may be involved in interactions with the 

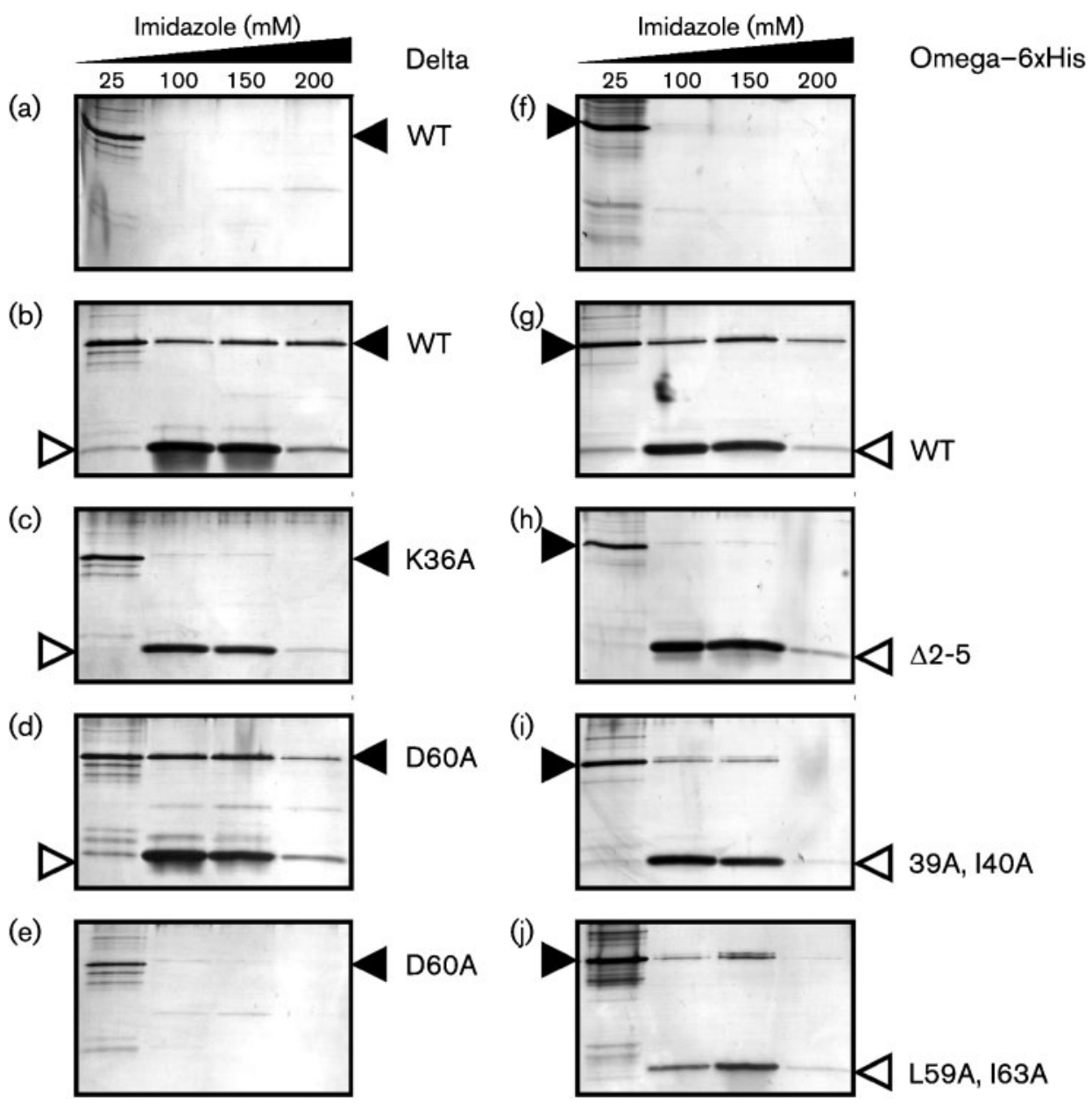

Fig. 4. Association of modified Delta and Omega proteins in vitro. Eluates obtained with increasing imidazole concentrations in wash buffer $(25,100,150$ and $200 \mathrm{mM})$ were analysed by SDS-PAGE and silver stained. (a-e) Purified Omega-6 $\times$ His protein (white arrowhead) was mixed with the soluble fraction of proteins obtained from strains producing different untagged variants of Delta protein (black arrowhead) (b-d) in the presence of $1.25 \mathrm{mM}$ ATP. In control experiments (a and e) purified His-tag was used instead of Omega- $6 \times$ His. $(f-j)$ Purified Omega- $6 \times$ His protein or its variants (white arrowhead) were mixed in the presence of $1.25 \mathrm{mM}$ ATP with the soluble fraction of proteins obtained from strains producing Delta protein (black arrowhead) $(g-j)$. In the control $(f)$ the soluble fraction of proteins containing Delta was mixed with purified His-tag instead of Omega$6 \times$ His.

ParF ATPase, the Delta homologue in this system (Golovanov et al., 2003). In order to verify the role of the N-terminal part of Omega (not essential for Omega dimerization) in the interaction with Delta, Omega variants deprived of a different number of $\mathrm{N}$-terminal amino acids (plasmids pMS4005, pMS4010 and pMS4018) were tested in the two-hybrid system together with Delta. Analysis of $\beta$-galactosidase activity in double transformants of E. coli GS1129 showed that removal of 17, 9 or even 4 amino acids located in the $\mathrm{N}$ terminus of Omega strongly affected Omega interaction with Delta: the lacZ activity was $60 \%$ of control (11\% for WT Omega) (Fig. 2b, i).

The role of the N-terminal part of the Omega protein in its interaction with Delta was also tested in vitro. The Omega $\Delta 2-5-H i s$ variant was produced from plasmid
pET $\omega 5 \mathrm{NH}$ and used for Delta co-purification. Omega $\Delta 2-$ 5 failed to associate with Delta in vitro (Fig. 4h).

A more detailed analysis of the Omega $\mathrm{N}$ terminus was then attempted. Each of the three N-terminal amino acids was substituted with alanine (plasmids pMS4001A, pMS4002A and pMS4023A). These constructs, paired with pDP2000 (LexA ${ }^{408}$ Delta), were used for co-transformation of E. coli GS1129. Analysis of $\beta$-galactosidase activity showed that both the single and double amino acid substitutions in the $\mathrm{N}$-terminal tip of Omega had a slight negative effect on the ability of Omega to interact with Delta (twofold higher $\beta$-galactosidase activity than that with WT Omega) (Fig. 2b, i).

The Omega variants deficient in dimerization carrying substitutions of hydrophobic amino acids in the $\beta, \alpha 1$ or $\alpha 2$ 
structures were also tested for their ability to associate with Delta (plasmid pMS2000 paired with pDP4030A, pDP4039A or pDP4059A). The analysed amino acid substitutions hardly affected the Omega-Delta interaction. The relative $\beta$-galactosidase activities in strains carrying plasmids with these mutations were $15 \%(\beta), 6 \%(\alpha 1)$ and $11 \%(\alpha 2)$ compared with $7 \%$ for the WT Omega (Fig. $2 c, i)$.

Aditionally, Omega variants I39A I40A and L59A I63A substitutions were produced from plasmids pET $\omega 39 \mathrm{AH}$ and pET59AH. The ability of these purified Omega-His variants to interact with Delta in the presence of ATP was analysed in vitro. Omega I39A I40A and L59A I63A were still able to associate with Delta, albeit somewhat weaker than WT Omega (Fig. 4i, j).

\section{DISCUSSION}

The first attempts in our laboratory to demonstrate Omega dimerization in vivo with the use of a yeast two-hybrid system were unsuccessful (Sitkiewicz, 2002). This was thought to be due to improper folding of the hybrid protein. The use of a bacterial two-hybrid system in the present study allowed demonstration of Omega-Omega interactions in vivo; the $\beta$-galactosidase activity of a strain carrying Omega fusions with two LexA DBDs was about 20 -fold lower than that observed for a non-repressed negative control (expressing non-fused LexA DBDs) (Fig. 1). However, we also observed slight repression of lac $Z$ in control strains carrying pairs of plasmids with Omega fused to only one LexA DBD. It is possible that Omega, a DNA-binding protein, represses the reporter gene by a non-specific interaction with its promoter region, or a dimer of the Lex $\mathrm{A}_{\mathrm{DBD}}-$ Omega hybrid protein is able to recognize both arms of the artificial LexA operator and interfere with the transcriptional machinery. Nevertheless, specific Omega dimerization has been clearly demonstrated using this system. Omega translational fusion proteins were also used to analyse the Delta-Omega interaction. The detected interactions were weaker than those seen in the Omega dimerization assay, although strong enough to allow analysis of the mutated alleles of both genes. The results of the Delta and Omega mutant analysis using a bacterial two-hybrid system supported by in vitro studies on purified proteins are summarized in Fig. 5.

The analysis of Omega structure performed by Murayama et al. (2001) has predicted that the dimerization depends on hydrophobic residues in the C-terminal helical structures of the protein. Similar observations based on structural studies were made for the ParG protein from TP228 (Golovanov et al., 2003). Here, we directly showed that alanine substitution of two hydrophobic residues in the $\alpha 1$ (I39A and I40A) or $\alpha 2$ helix (L59A and I63A) (Supplementary Fig. S2) precluded Omega dimerization (Fig. 2c, ii). Interestingly, the substitution of two hydrophobic residues in the $\beta$-ribbon (V30A and $\mathrm{V} 32 \mathrm{~A}$ ) also abolished dimerization of Omega in vivo. As Omega

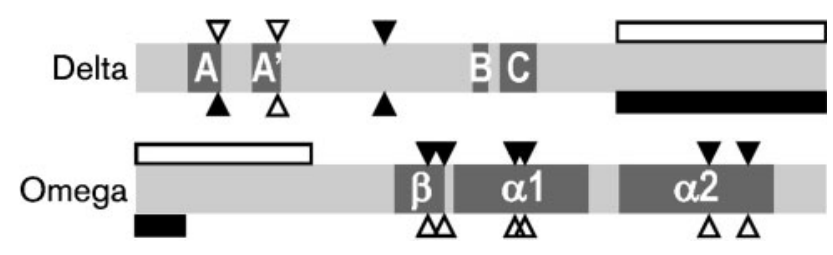

Fig. 5. Summary of mutant Delta and Omega protein features. Amino acids modified in Delta and Omega variants are indicated by arrowheads above and below the schematic protein representations. Black/white arrowheads indicate substantial/negligible effects, respectively, on homodimerization (symbols above bar) and interaction with the partner (below the bar). Deletions analysed are shown by rectangles.

binds specific DNA sequence as a dimer (de la $\mathrm{Hoz}$ et al., 2004), our results correlate with the observation that the T29A substitution in the $\beta$-ribbon, which did not change the conformation of Omega, reduced its DNA binding and $P \delta$ promoter repression (Welfle et al., 2005). A comparative analysis of RHH transcription regulators involved in plasmid partition showed that hydrophobic residues analysed in the present work are conserved in these positions of $\beta, \alpha 1$ and $\alpha 2$ structures (Supplementary Fig. S2) (Schreiter \& Drennan, 2007).

It was previously shown that the repressor activity of Omega was unaffected when the protein was deprived of 7 , 17 or $18 \mathrm{~N}$-terminal amino acids (Welfle et al., 2005). It was therefore postulated that the $\mathrm{N}$ terminus is not involved in Omega dimerization. In this work, we directly demonstrate that deletion of 5,10 or 18 amino acids had no effect on Omega self-association (Fig. 2b, ii, and Supplementary Fig. S2). In the partition system of TP228, deletion of 9 or 19 aa from the $\mathrm{N}$ terminus of ParG did not abolish ParG dimerization (Carmelo et al., 2005). Analysis of another RHH-type ParB protein (from pB171 plasmid) also confirms that its $19 \mathrm{~N}$-terminal amino acids are not involved in dimerization. In contrast, this region was indispensable for formation of high-molecular-mass complexes, suggesting its involvement in the pairing of parC centromeres (Ringgaard et al., 2007).

Golovanov et al. (2003) suggested that $\beta$-ribbons and $\alpha$ helices of the RHH protein ParG are involved in its interaction with its partition partner ParF. Our in vivo analysis of Omega derivatives with amino acid substitutions in $\beta, \alpha 1$ and $\alpha 2$ structures did not confirm this hypothesis; all three Omega variants impaired in selfassociation (Omega V30A V32A, Omega I39A I40A, and Omega L59A I63A) efficiently formed heterodimers with Delta (Fig. 2c and Supplementary Fig. S2). The Omega I39A I40A and L59A I63A variants could interact with Delta in vitro as well (Fig. 4i, j). This clearly suggests that the ability of Omega to dimerize is not a prerequisite for interaction with Delta, in contrast to what has been observed for type Ia ParB protein from $P$. aeruginosa (Bartosik et al., 2004). 
Omega variants lacking 17, 9 or 4 residues were tested for association with Delta. The lack of an interaction between the N-terminally truncated Omega and its partner protein Delta (both in vivo and in vitro) has clearly demonstrated that the unstructured $\mathrm{N}$ terminus of Omega is involved in interaction with Delta (Figs 2b and 4h). An analysis of this region by single or double amino acid substitutions also supported the above conclusion: these modifications weakened the interaction of Omega with Delta, although none eliminated the interactions completely (Fig. 2b).

Our results clearly demonstrate that the C-terminal part of Omega is the dimerization domain, whereas the unstructured $\mathrm{N}$-terminal part does not participate in dimerization but is indispensable for Omega-Delta interactions (Fig. 5). These results correlate with the previous observation that deletion of $19 \mathrm{~N}$-terminal amino acids had a marginal stimulating effect on Delta ATPase activity and polymerization (Pratto et al., 2008). As for other systems, an involvement of the ParG N terminus in interaction with ParF was confirmed by the observed ability of ParG to promote ParF polymerization (Barillà et al., 2007). Machón et al. (2007) have shown that such ParF stimulation is not fully specific since it can also be brought about by heterologous ParG-like proteins from the pTAR and pB171 partition systems.

The mutational analysis of Delta Walker A motif (VILNNYFKGGVGKSKL) showed that substitution of the conserved lysine residue at position 36 with alanine or glutamic acid (K36A or K36E) had no effect on Delta dimerization (Fig. 2a and Supplementary Fig. S1), although such substitution abolished ATP binding by ParA of P1 (Davis et al., 1996). These observations contradict the results obtained for other ParA-like proteins showing the necessity of ADP or ATP binding for dimerization (Davey \& Funnell, 1994; Fung et al., 2001; Leonard et al., 2005). However, the crystal structure of Delta (Pratto et al., 2008) demonstrates a cleft in the Delta dimer which allows free exchange of ATP and ADP. These authors also observed dimers of Delta in solution in the presence of ATP or ADP, but also in the absence of a nucleotide.

Delta protein derivatives with single amino acid substitutions (K36A or K36E) in the Walker A motif still capable of dimerization have lost their ability to associate with Omega (Figs 2a and $4 \mathrm{c}$ and Supplementary Fig. S1). The lack of interaction of these Delta mutants with Omega can indicate the necessity of ATP binding for such interactions. Also the results of the in vitro Delta-Omega co-purification assay clearly show that ATP is required for the Delta-Omega association (Fig. 3). These results explain the observed inability of Delta K36A to promote plasmid pairing (Pratto et al., 2008).

Our study also demonstrated that substitution of a conserved aspartic acid in the $\mathrm{A}^{\prime}$ motif with alanine (Delta D60A derivative) affected neither Delta dimerization nor its interaction with Omega (Figs 2a, 4d and 5). Pratto et al. (2009) found that a D60A substitution severely affected the disassembly of a complex formed in vitro by the Delta and
Omega proteins bound to the centromeric sequence. An equivalent substitution in Soj (D44A; Supplementary Fig. S1) abolished ATP hydrolysis but not ATP binding (Leonard et al., 2005). It could be hypothesized that ATP hydrolysis provokes and/or is necessary for the disassembly of Delta and Omega proteins and, as a consequence, plasmid pair separation. The L104A I105A Delta variant, with modifications of two hydrophobic residues in the highly conserved region between the $\mathrm{A}^{\prime}$ and $\mathrm{B}$ motifs was unable to dimerize (Fig. 5 and Supplementary Fig. S1). This region has previously been indicated as being responsible for homodimerization of the chromosomally encoded ParA protein of $P$. aeruginosa and interaction with its ParB partner (K. Lasocki and G. Jagura-Burdzy, unpublished data). The L104A and I105A amino acid substitutions resulted in the inability of Delta to both dimerize and interact with Omega (Fig. 2a). Since the level of hybrid protein LexA-Delta L104A I105A is comparable with LexA-Delta or LexA-Delta D60A (Supplementary Fig. S3) the instability of this hybrid cannot be responsible for the lack of interactions. These data seem to confirm the necessity of Delta dimerization for its interaction with Omega and indicate that the partition ATPases have a highly similar organization and function regardless of being encoded by plasmids or chromosomes.

An interesting observation is that the Delta variant deprived of the $\mathrm{C}$ terminus (Delta $\Delta 198$-284) can dimerize but cannot associate with Omega. This would identify the $\mathrm{C}$ terminus of Delta as the region of interaction with Omega. It has been shown previously (Kim \& Shim, 1999; Ravin et al., 2003) that the C-terminal amino acids of $\mathrm{F}$ SopA protein are essential for its interaction with SopB.

In summary, our study not only complements the in vitro analyses of Delta and Omega proteins but also provides important new information. Delta dimerization does not require ATP binding. The conserved region with L104 and I105 seems to be important for the dimerization as well as for interactions with Omega. The ability to interact with Omega is conditioned by Delta binding of ATP and the presence of an intact $C$ terminus. Omega dimerization involves not only its $\alpha$-helices but also the $\beta$-sheet. Omega can interact with Delta as a monomer and the unstructured $\mathrm{N}$-terminal part of Omega is involved in this interaction.

\section{ACKNOWLEDGEMENTS}

This project was funded by the Ministry of Science and Higher Education grant no. 4100/P01/2007/32 and partially by grant nos PBZ-MNiSW-04/I/2007 and 0644/B/P01/2009/37. The project is the continuation of M. D.'s work initiated in Dr P. Ceglowski's group. We thank Professor G. Stauffer for providing E. coli strain GS1129 and plasmids pDP804 and pMS604 (through Professor M. Hryniewicz).

\section{REFERENCES}

Akhtar, P., Anand, S. P., Watkins, S. C. \& Khan, S. A. (2009). The tubulin-like RepX protein encoded by the pXO1 plasmid forms polymers in vivo in Bacillus anthracis. J Bacteriol 191, 2493-2500. 
Barillà, D. \& Hayes, F. (2003). Architecture of the $\operatorname{ParF}^{\star}$ ParG protein complex involved in prokaryotic DNA segregation. Mol Microbiol 49, 487-499.

Barillà, D., Rosenberg, M. F., Nobbmann, U. \& Hayes, F. (2005). Bacterial DNA segregation dynamics mediated by the polymerizing protein ParF. EMBO J 24, 1453-1464.

Barillà, D., Carmelo, E. \& Hayes, F. (2007). The tail of the ParG DNA segregation protein remodels ParF polymers and enhances ATP hydrolysis via an arginine finger-like motif. Proc Natl Acad Sci U S A 104, 1811-1816.

Bartosik, A. A. \& Jagura-Burdzy, G. (2005). Bacterial chromosome segregation. Acta Biochim Pol 52, 1-34.

Bartosik, A. A., Lasocki, K., Mierzejewska, J., Thomas, C. M. \& Jagura-Burdzy, G. (2004). ParB of Pseudomonas aeruginosa: interactions with its partner ParA and its target parS and specific effects on bacterial growth. J Bacteriol 186, 6983-6998.

Behnke, D., Golubkov, V. I., Malke, H., Boitsov, A. S. \& Totolian, A. A. (1979). Restriction endonuclease analysis of group A streptococcal plasmids determining resistance to macrolides, lincosamides and streptogramin-B antibiotics. FEMS Microbiol Lett 6, 5-9.

Bignell, C. \& Thomas, C. M. (2001). The bacterial ParA-ParB partitioning proteins. J Biotechnol 91, 1-34.

Bouet, J. Y. \& Funnell, B. E. (1999). P1 ParA interacts with the P1 partition complex at parS and an ATP-ADP switch controls ParA activities. EMBO J 18, 1415-1424.

Bouet, J.-Y., Ah-Seng, Y., Benmeradi, N. \& Lane, D. (2007). Polymerization of SopA partition ATPase: regulation by DNA binding and SopB. Mol Microbiol 63, 468-481.

Bradford, M. M. (1976). A rapid and sensitive method for the quantitation of microgram quantities of protein utilizing the principle of protein-dye binding. Anal Biochem 72, 248-254.

Carmelo, E., Barillà, D., Golovanov, A. P., Lian, L. Y., Derome, A. \& Hayes, F. (2005). The unstructured N-terminal tail of ParG modulates assembly of a quaternary nucleoprotein complex in transcription repression. J Biol Chem 280, 28683-28691.

Davey, M. J. \& Funnell, B. E. (1994). The P1 plasmid partition protein ParA. A role for ATP in site-specific DNA binding. J Biol Chem 269, 29908-29913.

Davey, M. J. \& Funnell, B. E. (1997). Modulation of the P1 plasmid partition protein ParA by ATP, ADP, and P1 ParB. J Biol Chem 272, 15286-15292.

Davis, M. A., Radnedge, L., Martin, K. A., Hayes, F., Youngren, B. \& Austin, S. J. (1996). The P1 ParA protein and its ATPase activity play a direct role in the segregation of plasmid copies to daughter cells. Mol Microbiol 21, 1029-1036.

de la Hoz, A. B., Ayora, S., Sitkiewicz, I., Fernández, S., Pankiewicz, R., Alonso, J. C. \& Ceglowski, P. (2000). Plasmid copy-number control and better-than-random segregation genes of pSM19035 share a common regulator. Proc Natl Acad Sci U S A 97, 728-733.

de la Hoz, A. B., Pratto, F., Misselwitz, R., Speck, C., Weihofen, W., Welfle, K., Saenger, W., Welfle, H. \& Alonso, J. C. (2004). Recognition of DNA by omega protein from the broad-host range Streptococcus pyogenes plasmid pSM19035: analysis of binding to operator DNA with one to four heptad repeats. Nucleic Acids Res 32, 3136-3147.

Dimitrova, M., Younès-Cauet, G., Oertel-Buchheit, P., Porte, D., Schnarr, M. \& Granger-Schnarr, M. (1998). A new LexA-based genetic system for monitoring and analyzing protein heterodimerization in Escherichia coli. Mol Gen Genet 257, 205-212.

Dmowski, M., Sitkiewicz, I. \& Ceglowski, P. (2006). Characterization of a novel partition system encoded by the delta and omega genes from the streptococcal plasmid pSM19035. J Bacteriol 188, 43624372.

Fogel, M. A. \& Waldor, M. K. (2006). A dynamic, mitotic-like mechanism for bacterial chromosome segregation. Genes Dev 20, 3269-3282.

Fung, E., Bouet, J. Y. \& Funnell, B. E. (2001). Probing the ATPbinding site of P1 ParA: partition and repression have different requirements for ATP binding and hydrolysis. EMBO J 20, 49014911.

Funnell, B. E. (1991). The P1 plasmid partition complex at parS. The influence of Escherichia coli integration host factor and of substrate topology. J Biol Chem 266, 14328-14337.

Gerdes, K., Møller-Jensen, J. \& Bugge Jensen, R. (2000). Plasmid and chromosome partitioning: surprises from phylogeny. Mol Microbiol 37, 455-466.

Gerdes, K., Møller-Jensen, J., Ebersbach, G., Kruse, T. \& Nordström, K. (2004). Bacterial mitotic machineries. Cell 116, 359-366.

Golovanov, A. P., Barillà, D., Golovanova, M., Hayes, F. \& Lian, L.-Y. (2003). ParG, a protein required for active partition of bacterial plasmids, has a dimeric ribbon-helix-helix structure. Mol Microbiol 50, 1141-1153.

Hanahan, D. (1983). Studies on transformation of Escherichia coli with plasmids. J Mol Biol 166, 557-580.

Hanai, R., Liu, R., Benedetti, P., Caron, P. R., Lynch, A. S. \& Wang, J. C. (1996). Molecular dissection of a protein SopB essential for Escherichia coli F plasmid partition. J Biol Chem 271, 1746917475.

Hayes, F. \& Barillà, D. (2006). Assembling the bacterial segrosome. Trends Biochem Sci 31, 247-250.

Kim, S. K. \& Shim, J. (1999). Interaction between F plasmid partition proteins SopA and SopB. Biochem Biophys Res Commun 263, 113117.

Kulinska, A., Czeredys, M., Hayes, F. \& Jagura-Burdzy, G. (2008). Genomic and functional characterization of the modular broad-hostrange RA3 plasmid, the archetype of the IncU group. Appl Environ Microbiol 74, 4119-4132.

Laemmli, U. K. (1970). Cleavage of structural proteins during the assembly of the head of bacteriophage T4. Nature 227, 680-685.

Larsen, R. A., Cusumano, C., Fujioka, A., Lim-Fong, G., Patterson, P. \& Pogliano, J. (2007). Treadmilling of a prokaryotic tubulin-like protein, TubZ, required for plasmid stability in Bacillus thuringiensis. Genes Dev 21, 1340-1352.

Lasocki, K., Bartosik, A. A., Mierzejewska, J., Thomas, C. M. \& Jagura-Burdzy, G. (2007). Deletion of the parA (soj) homologue in Pseudomonas aeruginosa causes ParB instability and affects growth rate, chromosome segregation, and motility. J Bacteriol 189, 57625772 .

Leonard, T. A., Butler, P. J. \& Löwe, J. (2005). Bacterial chromosome segregation: structure and DNA binding of the Soj dimer - a conserved biological switch. EMBO J 24, 270-282.

Li, Y. G., Dabrazhynetskaya, A., Youngren, B. \& Austin, S. (2004). The role of Par proteins in the active segregation of the P1 plasmid. Mol Microbiol 53, 93-102.

Lim, G. E., Derman, A. I. \& Pogliano, J. (2005). Bacterial DNA segregation by dynamic SopA polymers. Proc Natl Acad Sci U S A 102, 17658-17663.

Lochowska, A., Iwanicka-Nowicka, R., Zaim, J., Witkowska-Zimny, M., Bolewska, K. \& Hryniewicz, M. M. (2004). Identification of activating region (AR) of Escherichia coli LysR-type transcription factor CysB and CysB contact site on RNA polymerase alpha subunit at the cysP promoter. Mol Microbiol 53, 791-806. 
Lukaszewicz, M., Kostelidou, K., Bartosik, A. A., Cooke, G. D., Thomas, C. M. \& Jagura-Burdzy, G. (2002). Functional dissection of the ParB homologue (KorB) from IncP-1 plasmid RK2. Nucleic Acids Res 30, 1046-1055.

Machón, C., Fothergill, T. J. G., Barillà, D. \& Hayes, F. (2007). Promiscuous stimulation of ParF protein polymerization by heterogeneous centromere binding factors. J Mol Biol 374, 1-8.

Miller, J. H. (1992). A Short Course in Bacterial Genetics: a Laboratory Manual and Handbook for Escherichia coli. Cold Spring Harbor, NY: Cold Spring Harbor Laboratory.

Møller-Jensen, J. \& Gerdes, K. (2007). Plasmid segregation: spatial awareness at the molecular level. J Cell Biol 179, 813-815.

Møller-Jensen, J., Ringgaard, S., Mercogliano, C. P., Gerdes, K. \& Löwe, J. (2007). Structural analysis of the ParR/parC plasmid partition complex. EMBO J 26, 4413-4422.

Morrissey, J. H. (1981). Silver stain for proteins in polyacrylamide gels: a modified procedure with enhanced uniform sensitivity. Anal Biochem 117, 307-310.

Murayama, K., Orth, P., de la Hoz, A. B., Alonso, J. C. \& Saenger, W. (2001). Crystal structure of omega transcriptional repressor encoded by Streptococcus pyogenes plasmid pSM19035 at 1.5 A resolution. J Mol Biol 314, 789-796.

Myles, G. M., Hearst, J. E. \& Sancar, A. (1991). Site-specific mutagenesis of conserved residues within Walker A and B sequences of Escherichia coli UvrA protein. Biochemistry 30, 3824-3834.

Pratto, F., Cicek, A., Weihofen, W. A., Lurz, R., Saenger, W. \& Alonso, J. C. (2008). Streptococcus pyogenes pSM19035 requires dynamic assembly of ATP-bound ParA and ParB on parS DNA during plasmid segregation. Nucleic Acids Res 36, 3676-3689.

Pratto, F., Suzuki, Y., Takeyasu, K. \& Alonso, J. C. (2009). Singlemolecule analysis of protein-DNA complexes formed during partition of newly replicated plasmid molecules in Streptococcus pyogenes. J Biol Chem 284, 30298-30306.

Quisel, J. D. \& Grossman, A. D. (2000). Control of sporulation gene expression in Bacillus subtilis by the chromosome partitioning proteins Soj (ParA) and Spo0J (ParB). J Bacteriol 182, 3446-3451.

Ravin, N. V., Rech, J. \& Lane, D. (2003). Mapping of functional domains in $\mathrm{F}$ plasmid partition proteins reveals a bipartite SopBrecognition domain in SopA. J Mol Biol 329, 875-889.

Ringgaard, S., Löwe, J. \& Gerdes, K. (2007). Centromere pairing by a plasmid-encoded type I ParB protein. J Biol Chem 282, 28216-28225.
Sambrook, J. \& Russell, D. (2001). Molecular Cloning. A Laboratory Manual. Cold Spring Harbor, NY: Cold Spring Harbor Laboratory.

Schägger, H. \& von Jagow, G. (1987). Tricine-sodium dodecyl sulfate-polyacrylamide gel electrophoresis for the separation of proteins in the range from 1 to $100 \mathrm{kDa}$. Anal Biochem 166, 368-379.

Schreiter, E. R. \& Drennan, C. L. (2007). Ribbon-helix-helix transcription factors: variations on a theme. Nat Rev Microbiol 5, 710-720.

Schumacher, M. A., Glover, T. C., Brzoska, A. J., Jensen, S. O. Dunham, T. D., Skurray, R. A. \& Firth, N. (2007). Segrosome structure revealed by a complex of ParR with centromere DNA. Nature 450, 1268-1271.

Sitkiewicz, I. (2002). The regulatory gene omega of plasmid pSM19035. $\mathrm{PhD}$ thesis, Department of Microbial Biochemistry, Institute of Biochemistry and Biophysics, Polish Academy of Sciences.

Studier, F. W. \& Moffatt, B. A. (1986). Use of bacteriophage T7 RNA polymerase to direct selective high-level expression of cloned genes. J Mol Biol 189, 113-130.

Suefuji, K., Valluzzi, R. \& RayChaudhuri, D. (2002). Dynamic assembly of MinD into filament bundles modulated by ATP, phospholipids, and MinE. Proc Natl Acad Sci U S A 99, 16776-16781.

Surtees, J. A. \& Funnell, B. E. (2001). The DNA binding domains of $\mathrm{P} 1 \mathrm{ParB}$ and the architecture of the P1 plasmid partition complex. J Biol Chem 276, 12385-12394.

van den Ent, F., Møller-Jensen, J., Amos, L. A., Gerdes, K. \& Löwe, J. (2002). F-actin-like filaments formed by plasmid segregation protein ParM. EMBO J 21, 6935-6943.

Welfle, K., Pratto, F., Misselwitz, R., Behlke, J., Alonso, J. C. \& Welfle, H. (2005). Role of the N-terminal region and of beta-sheet residue Thr29 on the activity of the omega2 global regulator from the broad-host range Streptococcus pyogenes plasmid pSM19035. Biol Chem 386, 881-894.

Williams, D. R., Motallebi-Veshareh, M. \& Thomas, C. M. (1993). Multifunctional repressor KorB can block transcription by preventing isomerization of RNA polymerase-promoter complexes. Nucleic Acids Res 21, 1141-1148.

Yanisch-Perron, C., Vieira, J. \& Messing, J. (1985). Improved M13 phage cloning vectors and host strains: nucleotide sequences of the M13mp18 and pUC19 vectors. Gene 33, 103-119.

Zielenkiewicz, U. \& Ceglowski, P. (2005). The toxin-antitoxin system of the streptococcal plasmid pSM19035. J Bacteriol 187, 6094-6105.

Edited by: E. M. Top 